\title{
Evaluation of Metal Concentrations in Food Packaging Materials: Relation to Human Health
}

\author{
Ali Duran ${ }^{a}$, Mustafa Tuzen ${ }^{a}$, and Mustafa Soylak ${ }^{b}$ \\ a Gaziosmanpasa University, Faculty of Science and Arts, Chemistry Department \\ 60250 Tokat, Turkey \\ b Erciyes University, Faculty of Sciences, Department of Chemistry \\ 38039 Kayseri, Turkey
}

\section{INTRODUCTION}

The extensive employment of novel food packaging materials has caused an increase in the migration of hazardous metals from these products into the packaged foods. Various materials are widely used and paper and paper derivatives are indeed one of the primary sources (1). Catalysts, thermal stabilizers, adhesives, lubricants, antioxidants, pigments, bleaching agents, printing inks, and different chemicals are used during the production processes (2) and can migrate from the printed surface to the food contact surface (3). The different types of papers are produced by pulping, bleaching, and treatment processes. Recycled paper and paperboard products are produced from sources such as newspapers, magazines, and cartons which are pulped with water and cleaned and de-inked with surfactants (4-6).

Legislation in the area of food contact materials and articles is very complex and constantly in progress. In the United States, the Food and Drug Administration (FDA) has published its own food ingredients and packaging guidelines for the industry (7-8). In Europe, the concern about the examination of packaging materials with regard to the content of toxic substances has substantially grown after introduction of the EC Directive (94/62/EC), which limits the level of the toxic heavy metals in packaging materials $(2,9-11)$. The "maximum permitted quantity of

\footnotetext{
*Corresponding author.
}

E-mail: msoylak@gmail.com

\begin{abstract}
The determination of iron, cobalt, nickel, manganese, cadmium, chromium, lead, and copper in 39 different food packaging materials from Turkey was performed by flame atomic absorption spectrometry (FAAS). The contents of the investigated packaging materials included cheeses, fast-foods, meats, candy, desserts, fish, milk-containing sweets, fresh pasta, mixed nuts, bagels, goodies, olives, cheesecake bars, pudding, coffee, patty, sausage, and pizza.

The packaging samples (7.48$134.4 \mathrm{~g} \mathrm{~m}^{-2}$ ) were immersed in $3 \%$ (v/v) acetic acid for 24 hours at $40{ }^{\circ} \mathrm{C}$ to allow for migration prior to the determination of the metal concentrations. Good accuracy was obtained as verified by the analysis of certified reference material (CRM) NIST-SRM 1570a Trace Elements in Spinach Leaves.

The analyte concentrations in the packaging material samples were found to range from 0.13 221.2, 0.32-11.1, 0.05-33.2, 0.05-101.9, 0.04-3.09, 0.23-4.10, $0.42-22.1$, and $0.03-58.2 \mu \mathrm{g} \mathrm{g}^{-1}$ for $\mathrm{Fe}, \mathrm{Co}, \mathrm{Ni}, \mathrm{Mn}, \mathrm{Cd}, \mathrm{Cr}, \mathrm{Pb}$, and $\mathrm{Cu}$, respectively.
\end{abstract}

the residual substance in the material or article expressed as $\mathrm{mg}$ per $\mathrm{dm}^{2}$ of the surface in contact with foodstuffs" (QM) restriction limits were established for $\mathrm{Cd}, \mathrm{Pb}$, and $\mathrm{Hg}$ by the Council of Europe Resolution AP (9) for paper, paperboard materials, and articles intended to come into contact with foodstuffs. The QM restriction quality limits (mg dm${ }^{-2}$ paper and paperboard) are $0.002 \mathrm{mg} \mathrm{dm}^{-2}$ for $\mathrm{Cd}, 0.003 \mathrm{mg}$ $\mathrm{dm}^{-2}$ for $\mathrm{Pb}$, and $0.002 \mathrm{mg} \mathrm{dm}^{-2}$ for $\mathrm{Hg}$ (9).

Due to the negative and positive influences and the importance of trace elements in the human body (12-17), many scientific studies have been published about the migration of contaminants from paper packaging materials to foods and evaluation of these products for direct or indirect food contact applications (18-25).

This paper describes the determination of Fe, Co, Ni, Mn, Cd, Cr, $\mathrm{Pb}$, and $\mathrm{Cu}$ in various food packaging materials by the application of migration studies. Cheeses, fast foods, meats, candy, desserts, fish, milk-containing sweets, fresh pasta, mixed nuts, bagels, goodies, olives, cheesecake bars, pudding, coffee, patty, sausages, and pizza are the foods studied with regard to their contact with packaging materials. The migration study proposed here is similar to official methods reported in the literature (26-29).

\section{EXPERIMENTAL}

\section{Instrumentation}

A Model 3110 flame atomic absorption spectrometer (PerkinElmer, Inc., Shelton, CT, USA) was used. All measurements were done in an air-acetylene flame. The instrumental operating conditions are listed in Table I. The parameters were set as recommended by the manufacturer. The detection limits for analyte elements for flame atomic absorption spectrometric determinations are given in Table II. 


\section{Standard Solutions and Reagents}

All reagents were of analytical reagent grade unless otherwise stated. The standard solutions of the analytes for calibration were prepared by diluting a stock solution of $1000 \mathrm{mg} \mathrm{L}^{-1}$ of the analyzed element (E. Merck, Darmstadt, Germany). Acetic acid used for the migration tests was also from E. Merck. The standard reference material (SRM) used to compare the accuracy of the method was NIST SRM 1570a Trace Elements in Spinach Leaves (National Institute of Science and Technology, Gaithersburg, MD, USA).

TABLE I

Instrumental Operating Conditions

\begin{tabular}{cccc}
\hline $\begin{array}{c}\text { Ele- } \\
\text { ment }\end{array}$ & $\begin{array}{c}\text { Wave- } \\
\text { length } \\
\text { (nm) }\end{array}$ & $\begin{array}{c}\text { Slit } \\
\text { Width }\end{array}$ & $\begin{array}{c}\text { Lamp } \\
\text { Current } \\
(\mathrm{mA})\end{array}$ \\
\hline $\mathrm{Fe}$ & 248.3 & 0.2 & 30 \\
$\mathrm{Co}$ & 240.7 & 0.2 & 30 \\
$\mathrm{Ni}$ & 232.0 & 0.2 & 30 \\
$\mathrm{Mn}$ & 279.5 & 0.2 & 20 \\
$\mathrm{Cd}$ & 228.8 & 0.7 & 8 \\
$\mathrm{Cr}$ & 357.9 & 0.7 & 12 \\
$\mathrm{~Pb}$ & 283.3 & 0.7 & 15 \\
$\mathrm{Cu}$ & 324.8 & 0.7 & 15 \\
\hline
\end{tabular}

TABLE II

The Detection Limits for Analyte Elements for FAAS Detection

\begin{tabular}{cl}
\hline Element & $\left(\mu \mathrm{g} \mathrm{g}^{-1}\right)$ \\
\hline $\mathrm{Fe}$ & 1.0 \\
$\mathrm{Co}$ & 1.4 \\
$\mathrm{Ni}$ & 0.9 \\
$\mathrm{Mn}$ & 2.9 \\
$\mathrm{Cd}$ & 0.02 \\
$\mathrm{Cr}$ & 0.7 \\
$\mathrm{~Pb}$ & 2.4 \\
$\mathrm{Cu}$ & 0.2 \\
\hline
\end{tabular}

\section{Samples of Packaging Materials}

A total of 39 different food packaging materials were obtained from local dealers in Kayseri City, Turkey. Prior to the beginning of the migration tests, each sample was cut into squares $(10 \times 10 \mathrm{~cm})$ and stored at $4{ }^{\circ} \mathrm{C}$ for about 6 hours. Then they were put into weighing bottles, desiccated in an oven at $105^{\circ} \mathrm{C}$ for 2 hours until constant weight was reached. The food packaging materials along with their specific mass $\left(7.48-134.4 \mathrm{~g} \mathrm{~m}^{-2}\right)$ values are listed in Table III.

\section{Migration Procedure}

Exactly $2 \mathrm{dm}^{2}$ of contact surface for each sample (the two sides of $1 \mathrm{dm}^{2}$ specimens) were cut into pieces and kept in $100 \mathrm{~mL}$ of a 3\% (v/v) metal-free solution of acetic acid for 24 hours at $40{ }^{\circ} \mathrm{C}$. At the end of this treatment, the contact liquid solution was analyzed by flame AAS for determination of the analyte metals.

The data were subjected to a statistical analysis and correlation matrices were produced to examine the interrelationships between the trace metal concentrations. A Student's $t$-test was employed to estimate the significance of the values.

\section{RESULTS AND DISCUSSION}

The results of the migration test (3\% v/v acetic acid) for $\mathrm{Fe}, \mathrm{Co}, \mathrm{Ni}$, $\mathrm{Mn}, \mathrm{Cd}, \mathrm{Cr}, \mathrm{Pb}$, and $\mathrm{Cu}$ determination are listed in Table IV. The data are expressed both as $\mu \mathrm{g}$ of heavy metal per $g$ of paper sample and also as $\mu \mathrm{g}$ of heavy metal per $\mathrm{dm}^{2}$ of paper sample. The accuracy of the presented method was evaluated by means of trace element determination in the NIST SRM 1570a Trace Elements in Spinach Leaves. The results in Table V show that the values were within or near the certified values, indicating that there was good agreement. The relative standard deviations of the determinations were less than $10 \%$. The Student's $t$-test was used in this study $(\mathrm{p}<0.05)$.

\section{Pb Concentrations}

Lead $(\mathrm{Pb})$ is a widely distributed environmental poison and when used in the manufacture of packaging materials is a source of contamination of the food. Therefore, the monitoring of $\mathrm{Pb}$ concentration becomes essential. According to the Turkish Food Codex, the $\mathrm{Pb}$ content of any paper in direct contact with food may not exceed $20 \mu \mathrm{g} \mathrm{g}^{-1}$ (29). The concentrations of $\mathrm{Pb}$ in this study were in the $0.42-22.1 \mu \mathrm{g} \mathrm{g}^{-1}\left(0.41-11.8 \mu \mathrm{g} \mathrm{dm}^{-2}\right)$ range. Some of the investigated samples had values above the quality limit ( $3 \mu \mathrm{g} \mathrm{dm}^{-2}$ ) established by the Council of Europe (9).

However, the mean value for the 39 investigated samples was near this quality limit. Paperboard packaging for patty (sample No. 26) at $11.8 \mu \mathrm{g} \mathrm{dm}^{-2}$ had four times higher values than the European Council quality limit. This high concentration may originate from the leadbased colored ink on the paper.

\section{Cd Concentrations}

The Council of Europe proposed the maximum Cd limit for packaging paper and board as $0.002 \mathrm{mg}$ $\mathrm{dm}^{-2}$ (9). In this study, the Cd content of all samples was below that limit. The values for $\mathrm{Cd}$ were in the 0.04-3.09 $\mathrm{Mg} \mathrm{g}^{-1}$ (0.03-0.64 $\mu \mathrm{g} \mathrm{dm}^{-2}$ ) range, with mean values of $0.81 \mu \mathrm{g} \mathrm{g}^{-1}$ and $0.31 \mu \mathrm{g} \mathrm{dm}^{2}$.

\section{Cr Concentrations}

The recommended daily intake of Cr by the National Research Council, Food and Nutrition Board is 50-200 $\mu \mathrm{g}(30,31)$. The Cr levels found in the materials used for this study ranged from $0.23-4.10 \mu \mathrm{g} \mathrm{g}^{-1}$, with a mean value $1.45 \mu \mathrm{g} \mathrm{g}^{-1}$. These values are also lower than the surface guideline limits of $3.05 \mu \mathrm{g} \mathrm{dm}^{-2}$ provided by the Council of Europe (9). 
TABLE III

Foods in Contact With Packaging Materials and Specific Mass Employed for Heavy Metals Determination by Flame AAS

\begin{tabular}{|c|c|c|}
\hline Sample & Food & Mass $\left(\mathrm{g} \mathrm{m}^{-2}\right)$ \\
\hline 1 & Cheese & 37.6 \\
\hline 2 & Fast food & 20.9 \\
\hline 3 & Meat & 19.2 \\
\hline 4 & Candy & 19.9 \\
\hline 5 & Fast food & 17.8 \\
\hline 6 & Fast food & 128.4 \\
\hline 7 & Dessert & 17.0 \\
\hline 8 & Fast food & 18.3 \\
\hline 9 & Fish & 21.3 \\
\hline 10 & Milky sweet & 37.0 \\
\hline 11 & Fresh pasta & 36.5 \\
\hline 12 & Fast food & 19.1 \\
\hline 13 & Mixed nuts & 31.0 \\
\hline 14 & Mixed nuts & 34.1 \\
\hline 15 & Fast food & 29.7 \\
\hline 16 & Bagel & 20.5 \\
\hline 17 & Fast food & 27.4 \\
\hline 18 & Goodies & 21.8 \\
\hline 19 & Olive & 60.6 \\
\hline 20 & Fast food & 15.9 \\
\hline 21 & Fast food & 24.9 \\
\hline 22 & Cheesecake bars & rs $\quad 28.1$ \\
\hline 23 & Pudding & 45.1 \\
\hline 24 & Fast food & 26.0 \\
\hline 25 & Coffee & 68.9 \\
\hline 26 & Patty & 126.1 \\
\hline 27 & Sausage & 43.8 \\
\hline 28 & Pizza & 54.3 \\
\hline 29 & Cheese & 22.2 \\
\hline 30 & Milky sweet & 27.4 \\
\hline 31 & Dessert & 17.8 \\
\hline 32 & Meat & 47.9 \\
\hline 33 & Fast food & 17.1 \\
\hline 34 & Milky sweet & 58.5 \\
\hline 35 & Candy & 7.48 \\
\hline 36 & Fast food & 21.5 \\
\hline 37 & Fast food & 134.4 \\
\hline 38 & Milky sweet & 54.0 \\
\hline 39 & Coffee & 14.8 \\
\hline
\end{tabular}

TABLE IV

Results of Migration Test (3\%, v/v, acetic acid) All data are expressed both as $\mu \mathrm{g}$ of heavy metal per $\mathrm{g}$ of sample and also as $\mu \mathrm{g}$ of heavy metal per $\mathrm{dm}^{2}$ of paper sample.

\begin{tabular}{|c|c|c|c|c|c|c|c|c|}
\hline \multicolumn{9}{|c|}{ Concentration } \\
\hline Sample & $\mathrm{Fe}$ & Co & $\mathrm{Ni}$ & $\mathrm{Mn}$ & $\mathrm{Cd}$ & $\mathrm{Cr}$ & $\mathrm{Pb}$ & $\mathrm{Cu}$ \\
\hline 1 & 67.8 & 0.41 & 0.02 & 4.40 & 0.42 & 0.74 & 4.44 & 0.50 \\
\hline 2 & 5.52 & 0.41 & 0.02 & 1.79 & 0.12 & 0.31 & 1.33 & 0.35 \\
\hline 3 & 7.26 & 0.41 & 0.02 & 0.61 & 0.41 & 0.31 & 0.55 & 0.20 \\
\hline 4 & 44.0 & 0.41 & 2.21 & 4.38 & 0.34 & 0.31 & 0.55 & 0.50 \\
\hline 5 & 3.13 & 0.41 & 0.02 & 0.83 & 0.34 & 0.31 & 2.88 & 0.04 \\
\hline 6 & 0.17 & 0.41 & 2.21 & 0.06 & 0.49 & 0.30 & 0.54 & 0.04 \\
\hline 7 & 3.13 & 0.41 & 0.02 & 0.72 & 0.49 & 0.31 & 2.09 & 0.20 \\
\hline 8 & 3.73 & 0.88 & 0.02 & 0.83 & 0.57 & 0.31 & 1.33 & 0.04 \\
\hline 9 & 23.9 & 0.41 & 0.02 & 2.64 & 0.12 & 0.31 & 0.55 & 0.66 \\
\hline 10 & 29.8 & 0.88 & 0.02 & 0.18 & 0.12 & 0.31 & 0.55 & 0.04 \\
\hline 11 & 6.10 & 1.35 & 0.02 & 0.82 & 0.42 & 0.73 & 4.42 & 3.27 \\
\hline 12 & 17.9 & 0.88 & 0.02 & 1.15 & 0.42 & 0.74 & 1.32 & 0.81 \\
\hline 13 & 29.8 & 0.88 & 0.02 & 13.1 & 0.64 & 0.73 & 0.55 & 0.50 \\
\hline 14 & 6.99 & 1.94 & 3.12 & 34.8 & 0.13 & 0.31 & 3.19 & 0.09 \\
\hline 15 & 6.50 & 1.95 & 0.59 & 1.09 & 0.18 & 0.31 & 0.61 & 0.83 \\
\hline 16 & 18.7 & 1.43 & 1.22 & 5.70 & 0.11 & 0.31 & 4.04 & 1.41 \\
\hline 17 & 2.59 & 0.40 & 1.85 & 0.10 & 0.10 & 0.31 & 0.61 & 7.29 \\
\hline 18 & 7.98 & 0.40 & 0.59 & 0.85 & 0.25 & 0.31 & 4.05 & 2.01 \\
\hline 19 & 30.9 & 1.95 & 3.11 & 4.32 & 0.15 & 0.31 & 4.90 & 2.00 \\
\hline 20 & 5.02 & 1.43 & 0.59 & 2.08 & 0.15 & 0.31 & 3.18 & 0.24 \\
\hline 21 & 8.91 & 2.46 & 3.11 & 1.46 & 0.13 & 0.31 & 4.91 & 4.21 \\
\hline 22 & 0.15 & 0.40 & 1.85 & 0.10 & 0.12 & 0.31 & 0.62 & 0.09 \\
\hline 23 & 6.00 & 3.49 & 5.01 & 2.46 & 0.13 & 0.31 & 4.92 & 0.53 \\
\hline 24 & 8.92 & 1.43 & 3.74 & 3.20 & 0.11 & 0.31 & 5.75 & 4.78 \\
\hline 25 & 0.15 & 0.40 & 1.85 & 0.10 & 0.03 & 0.31 & 0.61 & 26.8 \\
\hline 26 & 22.1 & 5.03 & 9.43 & 22.3 & 0.28 & 2.45 & 11.8 & 2.30 \\
\hline 27 & 13.3 & 1.43 & 3.11 & 4.95 & 0.15 & 0.74 & 4.04 & 21.8 \\
\hline 28 & 3.57 & 1.43 & 1.85 & 1.47 & 0.15 & 0.30 & 4.05 & 29.8 \\
\hline 29 & 7.48 & 2.46 & 3.11 & 1.22 & 0.11 & 0.31 & 4.91 & 0.68 \\
\hline 30 & 2.59 & 0.40 & 1.22 & 0.59 & 0.03 & 0.31 & 2.33 & 15.9 \\
\hline 31 & 0.15 & 0.40 & 0.85 & 0.72 & 0.09 & 0.31 & 2.88 & 0.69 \\
\hline 32 & 4.06 & 0.91 & 1.22 & 36.1 & 0.09 & 0.31 & 1.65 & 0.69 \\
\hline 33 & 2.60 & 0.40 & 0.86 & 2.96 & 0.09 & 0.31 & 0.41 & 0.49 \\
\hline 34 & 0.15 & 0.40 & 0.85 & 0.10 & 0.09 & 0.30 & 0.41 & 0.49 \\
\hline 35 & 0.15 & 0.40 & 2.48 & 0.10 & 0.09 & 0.31 & 0.41 & 0.48 \\
\hline 36 & 0.15 & 0.40 & 0.86 & 0.22 & 0.09 & 0.31 & 0.41 & 0.48 \\
\hline 37 & 14.8 & 1.95 & 3.75 & 16.1 & 0.35 & 2.02 & 5.36 & 2.77 \\
\hline 38 & 4.06 & 0.40 & 0.85 & 1.34 & 0.09 & 0.31 & 0.41 & 1.11 \\
\hline 39 & 4.04 & 0.91 & 0.85 & 2.95 & 0.09 & 0.31 & 0.41 & 1.10 \\
\hline
\end{tabular}




\begin{tabular}{|c|c|c|c|}
\hline \multicolumn{4}{|c|}{$\begin{array}{c}\text { TABLE V } \\
\text { Results of Analysis with Migra- } \\
\text { tion Test for SRM NIST-SRM } \\
\text { 1570a Trace Elements in } \\
\text { Spinach Leaves }(n=3)\end{array}$} \\
\hline $\begin{array}{l}\text { Ele- } \\
\text { ment }\end{array}$ & $\begin{array}{l}\text { Certified } \\
\text { Value } \\
\left(\mu \mathrm{g} \mathrm{g}^{-1}\right)\end{array}$ & $\begin{array}{c}\text { Our } \\
\text { Value } \\
\left(\mu \mathrm{g} \mathrm{g}^{-1}\right)\end{array}$ & $\begin{array}{r}\text { Re- } \\
\text { covery } \\
(\%)\end{array}$ \\
\hline Mn & $75.9 \pm 1.9$ & $71.3 \pm 1.6^{\mathrm{a}}$ & 93 \\
\hline Co & $0.39 \pm 0.05$ & N.D. ${ }^{b}$ & _. \\
\hline $\mathrm{Ni}$ & $2.14 \pm 0.10$ & $2.1 \pm 0.2$ & 98 \\
\hline $\mathrm{Cd}$ & $2.89 \pm 0.07$ & $2.66 \pm 0.2$ & 92 \\
\hline $\mathrm{Cu}$ & $12.2 \pm 0.6$ & $11.7 \pm 0.5$ & 95 \\
\hline
\end{tabular}

${ }^{a}$ Average \pm standard deviation.

${ }^{\mathrm{b}}$ N.D. $=$ Not determined.

\section{Fe Concentrations}

Exposure to excess Fe can lead to numerous pathological consequences such as colorectal cancer and heart disease (32). There is no suggested Fe limit for paper packaging materials. The average $\mathrm{Fe}$ content of the studied samples was $36.9 \mu \mathrm{g} \mathrm{g}^{-1}$ and $13.9 \mu \mathrm{g} \mathrm{dm}^{-2}$. The FAO/WHO set a limit for heavy metal intake based on body weight. For an average adult (60 kg body weight), the provisional tolerable daily intake (PTDI) is $214 \mu \mathrm{g} \mathrm{Pb}$, $48 \mathrm{mg} \mathrm{Fe}, 3 \mathrm{mg} \mathrm{Cu}$, and $60 \mathrm{mg} \mathrm{Zn}$, respectively (33).

\section{Ni Concentrations}

The Ni concentrations in the samples were in the 0.05-33.2 $\mu \mathrm{g} \mathrm{g}^{-1}$ and $0.02-9.43 \mu \mathrm{g} \mathrm{dm}^{-2}$ range. There is no information available in the literature for maximum allowable nickel levels. However, the WHO (World Health Organization) recommends a maximum daily intake of 100-300 $\mu \mathrm{g} \mathrm{Ni} \mathrm{(34).} \mathrm{Thus,}$ the nickel levels found in the samples can be considered as not being a health risk.

\section{Co Concentrations}

In the literature, no information is available for safe cobalt levels in food packaging paper. The maximum concentration of Co for the cheese packaging material tested in this study was $2.46 \mu \mathrm{g} \mathrm{dm}^{-2}$ (11.1 $\mathrm{\mu g} \mathrm{g}^{-1}$ ), indicating that there are no health safety concerns from the cobalt content of packing materials.

\section{Mn Concentrations}

The U.S. Institute of Medicine recommends that $\mathrm{Mn}$ intake from food, water, and dietary supplements should not exceed the tolerable daily upper limit of $11 \mathrm{mg}^{\mathrm{day}}{ }^{-1}$ (30). In our study, the Mn levels were in the $0.05-101.9 \mu \mathrm{g} \mathrm{g}^{-1}$ range with $4.61 \mu \mathrm{g} \mathrm{dm}^{-2}$ as the mean surface value, indicating that there are no health safety concerns for this type of packaging material.

\section{Cu Concentrations}

The average daily dietary requirement for $\mathrm{Cu}$ in the adult human has been estimated to be $3 \mathrm{mg}$ (33). The Cu values in our work were found to range from $0.03-58.2 \mu \mathrm{g} \mathrm{g}^{-1}$, with a mean value for contact surface as $3.39 \mu \mathrm{g} \mathrm{dm}^{-2}$, indicating that there are no health safety concerns.

\section{CONCLUSION}

The food industry and scientists are faced with great difficulties in the attempt to achieve migration control of toxic elements leaching into foods from their respective packaging materials. Only limited data are currently available for permissible maximum levels of toxic metals. Restriction limits have been established for cadmium, lead, and nickel by the Council of Europe for paper and paperboard materials and articles intended to come in contact with foodstuff. The Turkish Food Codex has a regulation for the lead content of packaging paper.

The samples investigated in this study show below maximum legal concentrations of $\mathrm{Fe}, \mathrm{Co}, \mathrm{Ni}, \mathrm{Mn}$, $\mathrm{Cd}, \mathrm{Cr}$, and $\mathrm{Cu}$, except for $\mathrm{Pb}$. Thus, in general, these packaging products pose no health risks with respect to maximum metal concen- trations. However, routine or even daily controls with official methods should be made available and required for better accuracy, ease, and repeatability in food packaging materials analysis.

$\overline{\text { Received February 18, } 2013 .}$

\section{REFERENCES}

1. I.S. Arvanitoyannis and L. Bosnea, Crit. Rev. Food Sci. 44, 63 (2004).

2. E. Skrzydlewska and M. Balcerzak, Talanta 62, 937 (2004).

3. E.L. Bradley, L. Castle, T.J. Dines, A.G. Fitzgerald, P. Tunon, S.M. Jickells, S.M. Johns, E.S. Layfield, K.A. Mountfort, H. Onoh, and I.A. Ramsay, Food Addit. Contam. 22, 490 (2005).

4. J.Y. Escabasse and D. Ottenio, Food Addit. Contam. 19, 79 (2002).

5. A. Ozaki, Y. Yamaguchi, T. Fujita, K. Kuroda and G. Endo, Food Chem. Toxicol. 42, 1323 (2004).

6. A. Ozaki, Y. Yamaguchi, T. Fujita, K. Kuroda and G. Endo, Food Addit. Contam. 22, 1053 (2005).

7. FDA, Food ingredients and packaging guidance for industry threshold of regulation (TOR), Guidance for submitting requests under 21 CFR 170.39, Threshold of regulation for substances used in food contact articles, U.S. Food and Drug Administration (11 March 1996; Revised April 2005).

8. J.H. Heckman, Regul. Toxicol. Pharm. 42, 96 (2005).

9. Resolution AP, Council of Europe, Paper and board materials and articles intended to come into contact with foodstuffs (2002).

10. Official Journal of the European Union, Directive 2004/12/EC of the European Parliament and of the Council of 11 February 2004 amending Directive 94/62/EC on packaging and packaging waste. 


\section{Atomic $_{\text {Spectroscopy }}^{\text {to }}$ \\ 1 Vol. 34(3), May/June 2013}

11. M.E. Conti, Heavy metals in food packagings: The state of the art. IFCS: Intergovernmental Forum on Chemical Safety Global Partnerships for Chemical Safety: Contributing to the 2020 goal, University of Rome, Italy (2008).

12. M. Soylak and M. Dogan, Fresen. Environ. Bull. 4, 35 (1995).

13. M. Soylak and M. Dogan, Anal. Lett. 29, 635 (1996).

14. M. Soylak, I. Narin, L. Elci and M. Dogan, Fresen. Environ. Bull. 8, 14 (1999).

15. M. Soylak and L. Elci, J. Trace Microprobe T. 18, 397 (2000).

16. S. Saracoglu, M. Soylak and L. Elci, Trace Elem. Elect. 18, 129 (2001).

17. F.A. Aydin and M. Soylak, Talanta 73, 134 (2007).

18. L. Castle, S.M. Jickells, J. Gilbert and N. Harrison, Food Addit. Contam. 7, 779 (1990).

19. D. Thompson, S.J. Parry and R. Benzing, J. Radioanal. Nucl. Ch. 217, 147 (1997).

20. L. Castle, C.P. Offen, M.J. Baxter and J. Gilbert, Food Addit. Contam. 14, 35 (1997).

21. D. Kolasa, B. Arndt, C. Jedras and K. Zorawska, Polymer 44, 614 (1999).

22. W. Summerfield and I. Cooper, Food Addit. Contam. 18, 77 (2001).

23. M.E. Soares, C. Carneiro and M.L. Bastos, Atom. Spectrosc. 23, 148 (2002).

24. K. Ki-Cheol, P. Yong-Bae, L. MyungJin, K. Jung-Beom, H. Jeong-Weon, K. Dae-Hwan, L. Jung-Bok and K. Jong-Chan, Food Res. Int. 41, 411 (2008).

25. E.M. Martinis, R.A. Olsina, J.C. Altamirano and R.G. Wuilloud, Talanta 78, 857 (2009).

26. AOAC International, Official methods of analysis of AOAC International. 2 vol., 16th edition. Arlington, VA, USA, Association of Official Analytical Chemists (1995).

27. M.E. Conti, Food Res. Int. 30, 343 (1997).
28. M.E. Conti and F. Botre, Food Control 8, 131 (1997).

29. Turkish Food Codex, Regulations published in the Official Gazette numbered 26878 and dated 16/05/2008

30. RDA, Recommended Dietary Allowances. 10th Edition. National Academy Press. Washington, D.C., USA (1989).

31. M.S. Bratakos, E.S. Lazos and S.M. Bratakos, Sci. Total Environ. 290, 47 (2002).

32. P. Ponka, M. Tenenbein, J.W. Eaton, Iron. In: Nordberg GF, Fowler BA, Nordberg M, Friberg LT (editors), Handbook on the toxicology of metals, Academic Press, 577-598 (2007).

33. FAO/WHO, Expert Committee on Food Additives, 53rd session, Rome, Italy (1-10 June, 1999).

34. FAO/WHO, Joint FAO/WHO foods standards programme (1994). 